\begin{tabular}{|c|c|}
\hline & $\begin{array}{l}\text { International Journal of Trend in Scientific } \\
\text { Research and Development (IJTSRD) }\end{array}$ \\
\hline 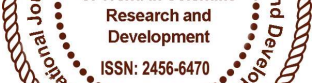 & International Open Access Journal \\
\hline 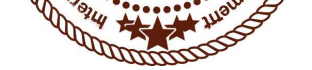 & ISSN No: 2456 - 6470 | www.ijtsrd.com | Volume - 2 | Issue - 2 \\
\hline
\end{tabular}

\title{
Thermal Stress Analysis of Homogeneous Orthotropic Plate with New Thermal Profiles Using First Order Shear Deformation Theory
}

\author{
Mr. A. K. Kanase \\ Associate Professor, Department of Civil \\ Engineering, BSCOER, Narhe, Pune, India
}

\author{
Mr. N. P. Khatmode \\ Assistant Professor, Department of Civil \\ Engineering, BSCOER, Narhe, Pune, India
}

\section{ABSTRACT}

Laminated composite plates are extensively used in Civil, Mechanical and Aerospace industries. A composite material is formed by combining two or more materials, so that the properties of the composites are different from those of the individual constituent's materials. Laminated composites formed by fibres are bound together using binding material called 'matrix'. The reinforcing fibers used in fibrous composites are having high modulus and ultimate strength. The matrix which is used to bind the fibers together should be able to transfer the loads to the fibers, as well as be able to protect the fibers from damage. Analytical models in single layered laminated orthotropic plate gives shear deformation and transverse normal thermal strains is validated for the thermal stress analysis subjected to gradient thermal profile across the thickness of laminate. First Order Shear Deformation Theory (FOST) is used for calculating various quantities and give good agreement with gradient thermal profile for thin plates. Based on these new results are prepared for additional three thermal profiles contains linear as well as parabolic path across thickness of plate with different boundary conditions.

Keywords: Composite, Orthotropic, Stress, Thermal, Analytical, Deformation

\section{INTRODUCTION}

Advancement of the technology of laminated materials, it is possible to use these materials in high temperature situations now days. Composites have no yield-limit, unlike metals and have a variety of failure modes, such as fiber failure, matrix cracking, interfiber failure and delamination, which give rise to a damage growing in service. Composite plates are subjected to significant temperature stresses due to different thermal properties of the adjacent laminas and therefore accurate predictions of thermally induced deformations and stresses represent a major concern in design of conventional structures. Nature of composite plates can be characterized by a complex $3 \mathrm{D}$ state of stress. Various theories and models are reported for the thermal stress analyses of the laminates. In this article First Order Shear Deformation Theory is used for calculating the results. Up to todays research scenario most of the researchers assumed linear gradient or constant thermal profiles along the thickness of plates and results for various quantities are validated for these thermal profiles. Single layered orthotropic square plate is assumed in this paper for preparation of new results. Material properties are shown in Table 1. The main objective of this paper is to suggest the linear and parabolic thermal profiles across thickness of the plate with different boundary conditions which is shown in Table 2. Thermal profiles variation through thickness is shown in Fig.1. Analytical solutions 
along with additional new results in normalization form are prepared.

First Order Shear Deformation Theory (FOST) considered in Reissner, (1945) and Mindlin (1951) for solutions to include the temperature effects on laminates. Rower et al.,(2001) removed deficiences in FOST incorporating third and fifth order displacement approximations through the plate thickness. 3D elasticity solution can estimate the correct results of the thermally induced quantities like displacements and stresses. Kant and Swaminathan (2002) incorporated formulations through there article Analytical solutions for static analysis of laminated composite and sandwich plates based on a higher order refined theory and suggested First Order Shear Deformation Theory as a special case with its importance. Kant et al. (2008) explored semianalytical solution for constant and linear temperature variation through the thickness of a laminate for composites and sandwiches. Kant and Shiyekar (2013) developed higher order theory for composite laminates subjected to thermal gradient by using (HOSNT12) model.

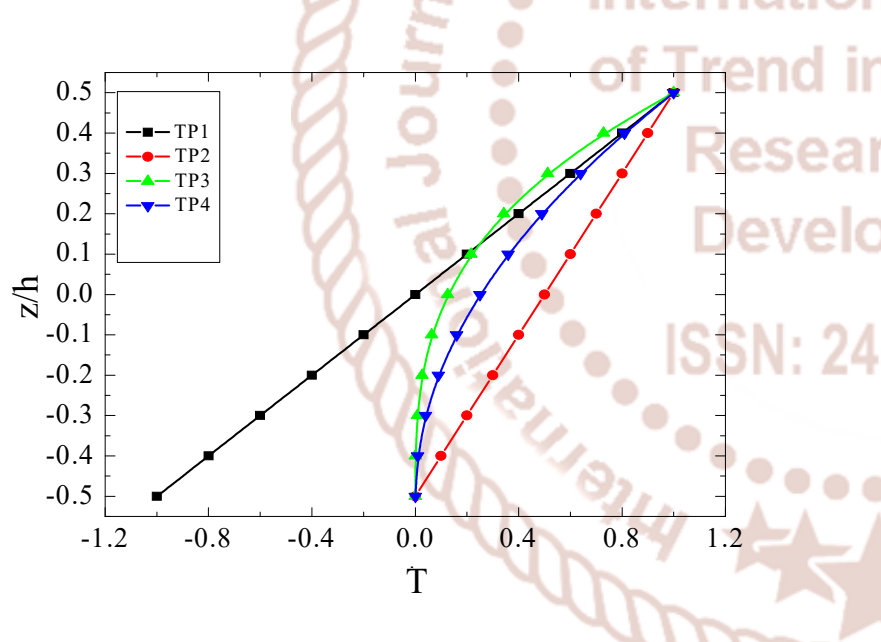

Fig. 1 Thermal loading variation of thermal profiles 1

to 4 across the thickness of the laminate.
Table 1 Material Properties for square $(a=b)$ single layer orthotropic plate

\begin{tabular}{|c|c|}
\hline $\begin{array}{l}\text { Material } \\
\text { Properties }\end{array}$ & $\begin{array}{l}E_{1}=150 \mathrm{GPa}, E_{2}=10 \mathrm{GPa}, \nu_{12}=0.3, \\
\nu_{21}=0.02 \\
G_{12}=G_{13}=5 G P a, G_{23}=3.378 G P a \\
\alpha_{x}=0.139 E-6 / \mathrm{k}, \alpha_{y}=9 E-6 / \mathrm{k}\end{array}$ \\
\hline $\begin{array}{l}\text { Normalizati } \\
\text { on }\end{array}$ & $\begin{array}{l}\bar{u}=\frac{u}{\alpha_{1} T_{0} h S^{\wedge} 3}, \quad \bar{v}=\frac{v}{\alpha_{1} T_{0} h S^{\wedge} 3}, \bar{w}=\frac{w}{\alpha_{1} T_{0} h S^{\wedge} 3} \\
\bar{\sigma}_{x}=\frac{\sigma_{x}}{\alpha_{1} T_{0} E_{2} S^{\wedge}}, \bar{\sigma}_{y}=\frac{\sigma_{y}}{\alpha_{1} T_{0} E_{2} S^{\wedge}}, \quad \bar{\tau}_{x y}=\frac{\tau_{y z}}{\alpha_{1} T} \\
\bar{\tau}_{x z}=\frac{\tau_{x z}}{\alpha_{1} T_{0} E_{2} S}, \quad \bar{\tau}_{y z}=\frac{\tau_{y z}}{\alpha_{1} T_{0} E_{2} S}\end{array}$ \\
\hline
\end{tabular}

Maximum normalized stress coordinates; $\bar{\sigma}_{x}$ and $\bar{\sigma}_{y}$ $(a / 2, b / 2, h / 2) ; \bar{\tau}_{x y}(0,0, h / 2)$. For analysis positive coordinates considered.

Maximum displacement coordinates, $\bar{u}:(0, b / 2, h / 2)$; $\bar{v}:(a / 2,0, h / 2) ; \bar{w}:(a / 2, b / 2,0)$

$E_{1}$ and $E_{2}$ : Modulus of Elasticity along laminate direction (x-axis) and transverse direction (y-axis). $\nu_{12}$ and $\nu_{21}$ : poisons ratio. $G_{12}, G_{13}, G_{23}$ : Modulus of rigidity.

$\alpha_{x}, \alpha_{y}$ : Thermal coefficients along $\mathrm{x}$ and y axes. $\mathrm{S}=$ $\mathrm{a} / \mathrm{h}$ : aspect ratio.

$\mathrm{a}, \mathrm{b}, \mathrm{h}$ : Dimensions of plate along $\mathrm{x}, \mathrm{y}$ and $\mathrm{z}$ directions. 
Table 2 Proposed thermal load profiles along thickness of plates

\begin{tabular}{|c|c|c|}
\hline $\begin{array}{l}\text { Therm } \\
\text { al } \\
\text { Profile }\end{array}$ & Equation of profile & $\begin{array}{l}(a / 2, b / 2, \\
z)\end{array}$ \\
\hline $\mathrm{TP}_{1}$ & $\begin{array}{l}T=\frac{2 z}{h} T_{0} \sin (\pi x / a) \sin (\pi y / b) \\
\text { (Gradient linear ) } \\
T_{0}=\text { Amplitude of Thermal } \\
\text { load. } \\
T=\text { Temperature difference. }\end{array}$ & $-T_{0} \leq T \leq T$ \\
\hline $\mathrm{TP}_{2}$ & $\begin{array}{l}T=\left(\frac{z}{h}+\frac{1}{2}\right) T_{0} \sin (\pi x / a) \sin ( \\
\text { (Gradient linear) }\end{array}$ & \\
\hline $\mathrm{TP}_{3}$ & $\begin{array}{l}T=\left(\frac{z}{h}+\frac{1}{2}\right)^{3} T_{0} \sin (\pi x / a) \sin (\pi \\
\text { (Parabolic degree 3) }\end{array}$ & \\
\hline $\mathrm{TP}_{4}$ & $\begin{array}{l}T=\left(\frac{z}{h}+\frac{1}{2}\right)^{2} T_{0} \sin (\pi x / a) \sin (\pi \\
\text { (Parabolic degree 2) }\end{array}$ & Rese \\
\hline
\end{tabular}

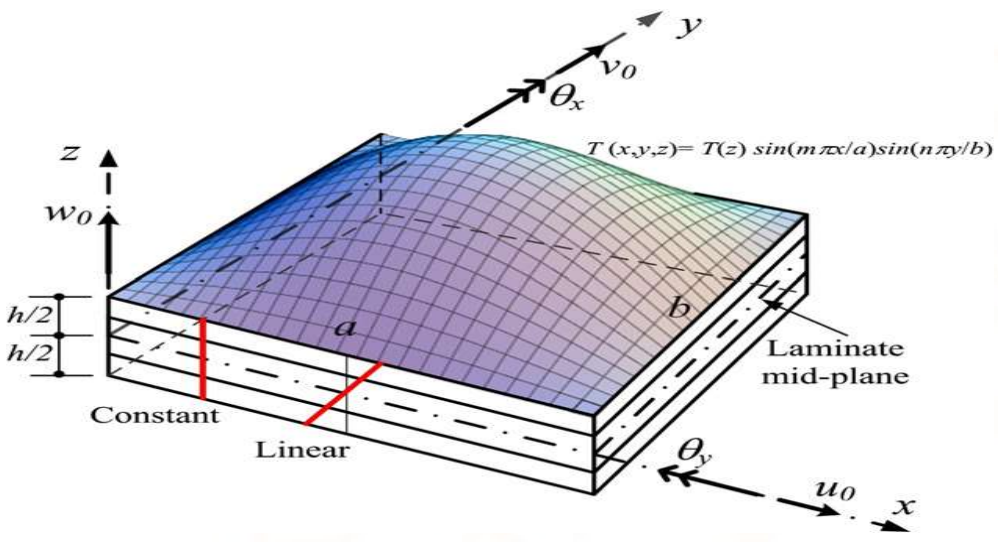

Fig. 2 Laminate geometry (diaphragm) with positive set of laminate reference axes, positive displacement components and typical thermal loading across the thickness of the lamina

$u(x, y, z), v(x, y, z), w(x, y, z)$ are the displacements in $x, y, z$ directions respectively, presented as -

$$
\begin{aligned}
& u=z \theta_{x} \cos \left(\frac{m \pi x}{a}\right) \sin \left(\frac{n \pi y}{b}\right), \\
& v=z \theta_{y} \sin \left(\frac{m \pi x}{a}\right) \cos \left(\frac{n \pi y}{b}\right), \\
& \text { Ch and } \\
& w=w_{0} \sin \left(\frac{m \pi x}{a}\right) \sin \left(\frac{n \pi y}{b}\right)
\end{aligned}
$$

\section{Formulations}

\section{A. Displacement model}

A simply supported single layer orthotropic laminated plate is presented along with analytical solution. The geometry of the laminate is such that the side ' $a$ ' is along ' $x$ ' axis and side ' $b$ ' is on ' $y$ ' axis. The thickness of the laminate is denoted by ' $h$ ' and is coinciding with ' $z$ ' axis. The reference mid-plane of the laminate is at $h / 2$ from top or bottom surface of the laminate as shown in the Fig. 2. Lamina axes and reference axes are coincides with each other.

The fiber direction of the single layered lamina is coinciding with ' $x$ ' axis of the laminate. Fig. 2 also illustrates the mid-plane positive set of displacements along $x-y-z$ axes.

\section{B. Constitutive Relationship-}

Stress-strain relationship for orthotropic laminate under linear thermal loading can be written as Stress-strain relation for $0^{0}$ layer .

$\left(\sigma_{x}, \sigma_{y}, \tau_{x y}, \tau_{y z}, \tau_{x z}\right)$ are the stresses and

$\left(\varepsilon_{x}, \varepsilon_{y}, \gamma_{x y}, \gamma_{y z}, \gamma_{x z}\right)$ are the strains with respect to

laminate coordinate system $(x-y-z)$.

Where $\varepsilon_{x}=\frac{\partial u}{\partial x}, \quad \varepsilon_{y}=\frac{\partial v}{\partial y}, \quad \varepsilon_{z}=\frac{\partial w}{\partial z}, \gamma_{x y}=\frac{\partial u}{\partial y}+\frac{\partial v}{\partial x}$,

$\gamma_{x z}=\frac{\partial u}{\partial z}+\frac{\partial w}{\partial x}, \gamma_{y z}=\frac{\partial v}{\partial z}+\frac{\partial w}{\partial y}$ 
$\left\{\begin{array}{l}\sigma_{x_{0}} \\ \sigma_{y_{0}} \\ \tau_{x_{0}}\end{array}\right\}=\left[\begin{array}{ccc}Q_{1_{0}} & Q_{z_{0}} & 0 \\ Q_{2 z_{0}} & Q_{2_{0}} & 0 \\ 0 & 0 & Q_{3 z_{0}}\end{array}\right]\left\{\begin{array}{c}\varepsilon_{x}-\alpha_{x} T \\ \varepsilon_{y}-\alpha_{y} T \\ \gamma_{x y}\end{array}\right\}$,
$\left\{\begin{array}{l}\tau_{x z_{0}} \\ \tau_{y z_{0}}\end{array}\right\}=\left[\begin{array}{cc}Q_{44_{0}} & 0 \\ 0 & Q_{55_{0}}\end{array}\right]\left\{\begin{array}{l}\gamma_{x z} \\ \gamma_{y z}\end{array}\right\}$

$\left[Q_{i j}\right]$ are transformed elastic constants or stiffness matrix and defined as per the following.

$Q_{11_{0}}=\frac{E_{1}}{1-v_{12} v_{21}}, Q_{12_{0}}=\frac{v_{12} E_{1}}{1-v_{12} v_{21}}, Q_{22_{0}}=\frac{E_{2}}{1-v_{12} v_{21}}, Q_{33_{0}}=Q_{33_{0}}=$ $Q_{55_{0}}=G_{23}, \frac{\nu_{21}}{E_{2}}=\frac{\nu_{12}}{E_{1}}$,

$\alpha_{x}, \alpha_{y}=$ Coefficient of thermal expansion in $\mathrm{x}, \mathrm{y}$

direction. (3)

Compliance matrix involves engineering properties

namely two extensional moduli $\left(E_{1}, E_{2}\right)$, two

Poisson's ratios $\left(v_{12}, v_{21}\right)$ and three shear moduli

$\left(G_{12}, G_{13}, G_{23}\right)$.

Table 3 Maximum normalized displacements ( ) and Stresses (, ) for single layered laminated square plate simply supported on all edges subjected to gradient thermal loading (TP1) (Aspect ratios 4,10,20)

\begin{tabular}{|c|c|c|c|c|c|c|c|c|c|}
\hline $\begin{array}{l}\mathrm{S}= \\
\mathrm{a} / \mathrm{h}\end{array}$ & SO & $\bar{u}$ & $\bar{v}$ & $\bar{w} N:$ & $\bar{\sigma}_{x} 6=647$ & $\bar{\sigma}_{y}$ & $\bar{\tau}_{x y}$ & $\bar{\tau}_{x z}$ & $\bar{\tau}_{y z}$ \\
\hline \multirow[t]{2}{*}{4} & $\mathrm{TP}_{1}$ & -0.0811 & -0.2865 & $\begin{array}{l}10.9618 \\
{[21.49]}\end{array}$ & $\begin{array}{l}1.9528 \\
{[-3.15]}\end{array}$ & $\begin{array}{l}-3.1077 \\
{[51.31]}\end{array}$ & $\begin{array}{l}-0.5774 \\
{[62.35]}\end{array}$ & $\begin{array}{l}1.2719 \\
{[37.66]}\end{array}$ & $\begin{array}{l}-1.2718 \\
{[47.61]}\end{array}$ \\
\hline & Kant.[5] & --------- & $-\ldots$ & 9.0226 & 2.0164 & -2.0538 & -0.3556 & 0.9239 & -0.8616 \\
\hline \multirow[t]{2}{*}{10} & $\mathrm{TP}_{1}$ & -0.0162 & -0.0228 & $\begin{array}{l}1.2226 \\
{[12.93]}\end{array}$ & $\begin{array}{l}0.4444 \\
{[-7.69]}\end{array}$ & $\begin{array}{l}-0.5670 \\
{[0.56]}\end{array}$ & $\begin{array}{l}-0.0613 \\
{[-1.56]}\end{array}$ & $\begin{array}{l}0.2542 \\
{[-0.89]}\end{array}$ & $\begin{array}{l}-0.2542 \\
{[0.99]}\end{array}$ \\
\hline & Kant.[5]- & --------- & -------- & 1.4042 & 0.4845 & -0.5638 & -0.0638 & 0.2565 & -0.2517 \\
\hline \multirow[t]{2}{*}{20} & $\mathrm{TP}_{1}$ & -0.0042 & -0.0046 & $\begin{array}{l}0.28 \\
{[4.32]}\end{array}$ & $\begin{array}{l}0.1172 \\
{[-2.16]}\end{array}$ & $\begin{array}{l}-0.1450 \\
{[0.12]}\end{array}$ & $\begin{array}{l}-0.0139 \\
{[-3.94]}\end{array}$ & $\begin{array}{l}0.0659 \\
{[-0.16]}\end{array}$ & $\begin{array}{l}-0.0659 \\
{[0.29]}\end{array}$ \\
\hline & Kant.[5]- & --------- & --------- & 0.2916 & 0.1198 & -0.1448 & -0.0141 & 0.066 & -0.0657 \\
\hline
\end{tabular}


International Journal of Trend in Scientific Research and Development (IJTSRD) ISSN: 2456-6470

Table 4 Maximum normalized displacements $(\bar{u}, \bar{v}, 100 \bar{w})$ and Stresses $\left(\bar{\sigma}_{x}, \bar{\sigma}_{y}, \bar{\tau}_{x y}, \bar{\tau}_{x z}, \bar{\tau}_{y z}\right)$ for single layered laminated square plate simply supported on all edges subjected to thermal loading $\mathrm{TP}_{2}, \mathrm{TP}_{3}$ and $\mathrm{TP}_{4}$.

(Aspect ratios 4,10,20)

\begin{tabular}{|l|l|l|l|l|l|l|l|l|l|}
\hline $\mathrm{A} / \mathrm{H}$ & $\mathrm{SO}$ & $\bar{u}$ & $\bar{v}$ & $\bar{w}$ & $\bar{\sigma}_{x}$ & $\bar{\sigma}_{y}$ & $\bar{\tau}_{x y}$ & $\bar{\tau}_{x z}$ & $\bar{\tau}_{y z}$ \\
\hline \multirow{3}{*}{4} & $\mathrm{TP}_{2}$ & -0.040 & -0.575 & 5.217 & 0.298 & -2.233 & -0.967 & 0.635 & -0.635 \\
\cline { 2 - 9 } & $\mathrm{TP}_{3}$ & -0.036 & -0.345 & 4.696 & -0.11 & -2.964 & -0.599 & 0.398 & -0.901 \\
\cline { 2 - 9 } & $\mathrm{TP}_{4}$ & -0.040 & -0.431 & 5.218 & 0.163 & -2.688 & -0.741 & 0.527 & -0.842 \\
\hline \multirow{3}{*}{10} & $\mathrm{TP}_{2}$ & -0.008 & -0.080 & 0.601 & 0.114 & -0.392 & -0.139 & 0.127 & -0.127 \\
\cline { 2 - 10 } & $\mathrm{TP}_{3}$ & -0.007 & -0.044 & 0.541 & 0.042 & -0.505 & -0.082 & 0.087 & -0.167 \\
\cline { 2 - 9 } & $\mathrm{TP}_{4}$ & -0.008 & -0.057 & 0.601 & 0.092 & -0.464 & -0.103 & 0.110 & -0.160 \\
\hline \multirow{2}{*}{20} & $\mathrm{TP}_{2}$ & -0.002 & -0.019 & 0.139 & 0.031 & -0.099 & -0.034 & 0.0329 & -0.0329 \\
\cline { 2 - 9 } & $\mathrm{TP}_{3}$ & -0.002 & -0.011 & 0.125 & 0.013 & -0.128 & -0.020 & 0.023 & -0.0428 \\
\cline { 2 - 9 } & $\mathrm{TP}_{4}$ & -0.002 & -0.013 & 0.139 & 0.026 & -0.118 & -0.025 & 0.0286 & -0.041 \\
\hline
\end{tabular}

\section{Conclusions}

First Order Shear Deformation Theory (FOST) with five degrees of freedom in primary displacement field is presented for thermal stress analysis of single layer homogeneous orthotropic laminated square plate. Thermal loading with doubly sinusoidal variation along $x$ and $y$ directions and linear or gradient thermal field (Thermal Profil1) along thickness direction is considered over the cross-ply laminates for validation purpose. The present FOST is assessed by comparison with Semi Analytical Model [SAM]. FOST provide good results in case of very thin laminates with aspect ratio (S) increases from 4 to 20 . Thermal profile 2 which is gradient thermal profile for same plate only boundary conditions of thermal load amplitudes are changed as shown in Table 2. So assumption is thermal profile 2 having base results for comparison of thermal profile 3 and 4 . Results canot be compaired with each other because all thermal profiles 2,3 and 4 are totally new therefore new results are presented in Table 4 for these additional thermal profiles. Hence finaly we predict these additinal thermal loadind path along thickness in single layer orthotropic plate design.

\section{References}

[1] Reissner, E. (1945) The effect of transverse shear deformation on the bending of elastic Plates, ASME J. Applied Mechanics. v. (12) pp. 69-77.

[2] Mindlin, R.D. (1951) Influence of rotatory inertia and shear deformation on flexural motions of isotropic elastic plates, ASME J. Applied Mechanics. v. (18) pp. 31-38.

[3] Rohwer, K, Rolfes, R. and Sparr, H. (2001) Higher-order theories for thermal stresses in layered plates, Int. J. Solids and Structures., v. (38) pp. 3673 3687.

[4] Kant, T. and Swaminathan, K. ( 2002) Analytical solutions for static analysis of laminated composite and sandwich plates based on a higher order refined theory, Composite Structures. v. (56) pp. 329-344.

[5] Kant,T. Desai, Y. and Pendhari, S. (2008) An efficient semi-analytical model for composite and sandwich plate subjected to thermal load, Journal of Thermal Stresses. v. (31) pp. 77-103.

[6] Kant, T. and Shiyekar, S.M. (2013) An assessment of a higher order theory for composite laminates subjected to thermal gradient, Composite Structures.v.( 96) pp. 698-707. 